\title{
Financing of Liabilities Beyond the Service Life of Nuclear Installations
}

\author{
L. Havlíček
}

\begin{abstract}
Operation of a nuclear installation is connected with the creation of long-term liabilities for spent fuel management and disposal, and also decommissioning of the installation (power plant, storages). This means that the operator will have to expend considerable amount of financial resources over a long period after the closure of installation. These financial resources will have to be created during operation of the installation. Related costs to be expended in future must be fully included in the price of electricity, in order to ensure fair competition among different operators. Financial resources for future coverage of liabilities must be continuously invested in order to compensate for inflation and to gain some real interest.

Any failure by the operator to comply with its liabilities poses an economic and potentially an environmental hazard for operator's country. Due attention must therefore be paid to assessing connected costs, defining liabilities and ensuring appropriate regulatory oversight. Appropriate measures must be well defined and firmly anchored in the legislation of countries operating nuclear installations. This paper reviews the basic principles that should ensure operator's compliance their liabilities, and maps the current situation in the Czech Republic.
\end{abstract}

Keywords: Nuclear, operator, liabilities, financing, European Commission, fund, real interest, investment.

\section{Definition of liabilities}

\subsection{What is a "liability"?}

Generally, the term "liability" refers to any legal responsibility, duty or obligation, the state of one who is bound in law and justice to do something which may be enforced by action. Such liability may arise from contracts either express or implied or in consequence of torts committed.

According to International Accounting Standard IAS 37, liability is defined as an obligation to transfer economic benefits as a result of a past transaction or past events. The obligation can be legal (required by valid legislation) or construed. In this second case, a company (operator) has created a valid expectation that it will accept responsibilities by an established pattern of past practice, the company's published policies or a sufficiently specific current statement.

If we apply the above mentioned principle in the nuclear area, we should define events that can be considered as substantial for the formation of an obligation. At the same time, there must be a legal basis for distinct assignment of responsibility to the operator (legal obligation), or the operator should optionally accept responsibility.

\subsection{Spent nuclear fuel}

Nuclear fuel, in the case of a nuclear power plant usually in the form of fuel assemblies (bundles of tubes made from a special alloy filled with uranium dioxide with increased isotopic uranium 235 content), does not pose any substantial danger from radioactivity or from the toxic point of view for the environment until it is loaded into the reactor core and exposed to neutron flux, and chain reaction is started. Fission of atoms in uranium dioxide matrix leads to the creation of fission products.

As the number of completed fissions within the fuel assembly increases with time of residence of the fuel in the core, the radioactivity and toxicity and the related hazard to the environment also rises. At a certain point of time within the fuel assembly, the number of atoms susceptible to fission by the thermal neutrons is too low, and the number of atoms cap- turing thermal neutrons without subsequent fission is too high. A chain fission reaction is no longer sustainable under safe operational conditions. A part of most burned-up fuel assemblies must be replaced by fresh fuel assemblies. Fuel assemblies taken out of the reactor are called spent fuel assemblies (generally spent fuel).

Spent fuel is highly radioactive and toxic, as the original chemical composition from almost pure uranium dioxide is partly changed by fission into many other chemical elements, some of them with dangerous radiological and toxic properties. Therefore spent fuel must be reliably separated from its environment. What is more, spontaneous fission of fission products, which continues after discharge of the fuel from the core, produces substantial heat. As a result, the discharged fuel must be cooled down in the spent fuel pool for at least 5 years. This period (as well as radioactivity and toxicity) is dependent on fuel burn-up. Burn-up means megawatt-days of energy per metric ton of all uranium initially contained in the fuel assembly. The higher the burn-up, the longer the necessary cooling down period. Rising burn-up has been a general trend for many years.

When fuel assemblies have been cooled down sufficiently to be dealt with, they are usually placed into intermediate storage. The main purpose of this storage is to enable safe separation from the environment until geological disposal is in operation (or some other use of the spent fuel, e.g., reprocessing, partitioning and transmutation or some other as yet unknown technology) or until a sufficient batch of spent fuel has accumulated and can be disposed of economically. Additional cooling down and a decrease in radioactivity are also important factors.

Currently two main storage technologies are used. The older system is "wet" storage, i.e. in large pool with circulated water as cooling medium, in principle the same as the pool in a reactor building used to cool down spent fuel, and "dry" storage, which is based on large and heavy containers cooled by natural circulation of the air. The containers are in most cases also used also for transportation of spent fuel (dual purpose containers). This technology is currently more often chosen by nuclear power plant operators. 
Time of intermediate storage varies widely according to the utility / state spent fuel policy and strategy. In the case of reprocessing spent fuel, the storage time tends to be shorter (up to 20 years). However, in some countries intermediate storage up to 100 years is foreseen.

There are various concepts of future spent fuel disposal. Spent fuel can either be conditioned (fuel assemblies are decomposed in order to reduce volume) before being placed into disposal containers, or it can be disposed of without any processing. Disposal containers loaded with spent fuel are transported deep underground via access shaft or access tunnel. The disposal container is placed into a pre-planned position (usually a hole bored in a disposal corridor) and fixed with sealing material. The properties of deep disposal systems must ensure that the radiotoxic content of spent fuel is reliably contained (engineering barriers) and will not escape from the repository for several hundreds of thousands years, until the spent fuel is no longer dangerous for the environment.

If spent fuel is reprocessed, the separated uranium and plutonium can be re-used in the reactor (MOX and/or RepU fuel). Usually only one reprocessing cycle is carried out. Further recycling (reprocessing of MOX fuel) is difficult due to inconvenient isotopic composition with a high ratio of neutron absorbing isotopes. During the process of spent fuel reprocessing, the volume of waste is substantially reduced, as re-usable uranium and plutonium forms about $97 \%$ and the waste constitutes only $3 \%$ of the spent fuel volume. Highly radioactive waste is fixed in a matrix of borosilicate glass and placed into disposal containers. Such containers can be easily stored for a long period in slightly modified intermediary storage for spent fuel and disposed off in a deep geological repository, in the same manner as spent fuel.

Having in mind the back end of the fuel cycle we return to the question of the nuclear power plant operator's liability. The crucial moment for the emergence of liability is clearly when the first chain reaction after loading the fuel assembly is started, and the properties of the fuel assembly are irreversibly changed. This concept is widely used by utilities when assessing the liability for future expenditures connected with storage and disposal of spent fuel. Therefore only fuel which has been loaded into the reactor is considered as a liability, and not purchased fresh fuel before it has been loaded into the core.

\subsection{Radioactive waste}

During the operation of a nuclear power plant various radioactive wastes are generated. Wastes can be solid, liquid or gaseous. From the point of view of activity they can be classified as low, intermediate and high level waste. The wastes range from very short life isotopes (half-life in the order of minutes) to long-life isotopes. Major volumes of radioactive waste will also be generated during decommissioning of the plant.

Radioactive waste is usually treated with the aim of reducing the volume (e.g. burning, evaporation). Then the concentrated waste is fixed in bitumen, cement or glass matrix in stainless steel drums. These drums are disposed of in shallow near-surface repositories. When a section of the repository has been filled with drums, it is filled and covered with a concrete layer. Each repository has set limits and condi- tions, which define the maximum admissible inventory of disposed isotopes and activities. In principle, only solid and liquid short and medium life isotopes are disposed of in such near-surface repositories. Long-life waste is stored in intermediary storage to be removed to a deep geological repository when such a repository is available.

In comparison with spent fuel storage and disposal, the costs are substantially lower. Waste processing is performed during power plant operation, and very often these costs are a part of operational costs. However, for operational reasons some inventory of waste may accumulate. Long-life waste is stored. Near surface repositories will be monitored after closure for several hundred years. Therefore there is also a definite liability of operators to expend financial resources. The liability to store, process and dispose of a particular batch of waste originates when such a batch is generated. The liability to future operational, closure and monitoring costs connected with a near-surface repository originates when the waste is generated.

\subsection{Decommissioning of installations}

When the operation of a nuclear installation (a power plant in our case) comes to an end, it still contains spent fuel and radioactive waste. In addition some construction materials of the plant have been activated by ionizing radiation and have become radioactive. After a cooling down period, the spent fuel is removed from the plant, and the radioactive waste is processed and transferred to a repository or into storage. These expenditures are met from funds accumulated for the purpose of covering liabilities for spent fuel and radioactive waste. Decontamination and removal of activated construction materials are decommissioning the liability of the operator. Decommissioning refers to removal of all hazardous material from the plant and ensuring that the plant is no longer subject to regulation applicable for nuclear installations. Total removal of the plant and restoration of "green field" status is not part of the decommissioning liability.

There are three basic strategies for proceeding with decommissioning. Each has different implications for the liability of operator and for the connected costs.

Table 1: Basic decommissioning strategies

\begin{tabular}{|c|l|}
\hline Strategy & \multicolumn{1}{c|}{ Description } \\
\hline $\begin{array}{c}\text { Immediate } \\
\text { Decommissioning }\end{array}$ & $\begin{array}{l}\text { Decommissioning is completed as } \\
\text { soon as possible }\end{array}$ \\
\hline $\begin{array}{c}\text { Combined } \\
\text { (partial immediate } / \\
\text { deferred) } \\
\text { Decommissioning } \\
\text { Only decontaminations and removal } \\
\text { of lowly-activated materials per- } \\
\text { formed immediately, highly acti- } \\
\text { vated structures are left intact for } \\
\text { years to decrease their activity and } \\
\text { only then removed }\end{array}$ \\
\hline $\begin{array}{c}\text { Deferred } \\
\text { Decommissioning }\end{array}$ & $\begin{array}{l}\text { After removal of spent fuel and } \\
\text { operational waste, the plant is left } \\
\text { intact for roughly 50 years }\end{array}$ \\
\hline
\end{tabular}

The decisive moment that creates the liability of an operator to decommission is the first start-up of the reactor (first chain reaction). 


\subsection{Division of responsibilities in reality}

The responsibility of a nuclear power plant operator to cover all liabilities dealt with here stems from the basic widely recognized principle that "the polluter pays". However in order to ensure that the liabilities are covered, state legislation establishes detailed regulations on how liability is to be assessed, how funds are to be accumulated, rules for investment and criteria for fulfillment of the liability. Legal responsibility is assumed by the state itself (a state agency, a ministry, via a selected contractor), or by organizations representing a group of operators (typically when there are several small operators with only one or two operated plants). The activities of entities are financed by the operators through regular fixed payments or through fees based on electricity produced. It is very important to ensure that different liabilities of the individual operators are assessed separately, and that there are no cross subsidies.

Historically, the situation has been handled differently from country to country. In many countries insufficient funds have been set aside. When the first generation of nuclear power plants was built, nuclear liabilities were not taken into account and contributions to such a fund was not an organic part of product (electricity) price. In the 1970s, the concept of a fund to cover liability was introduced in many countries, but it remains questionable how adequate these financial resources are. Especially in countries where there was no clear border between the civilian and military nuclear program, past nuclear liabilities will have to be covered from the state budget. Another question concerns, how efficiently the collected financial resources are being spent. The situation in the USA serves as a warning. Huge sums were paid by the utilities in the form of a fixed fee per kWh generated, but most of the have been spent without solving the problems or disposing of the accumulated spent fuel.

Nuclear liabilities have become the subject of high level political discussions among the European Parliament, the Council and the Commission. An inter-institutional statement issued in July 2003 set the ground for Community action, highlighting the need for adequate financial resources to cover nuclear liabilities. Recently there have been efforts on the European Community level to regulate this area in the member states. The European Commission has drafted several directives prescribing the division of responsibilities, the principles for accumulating financial resources, establishing funds and establishing an oversight role for European organs. This legislation met fierce resistance in some countries (to some degree all the countries that operate nuclear power plants, but mainly France and Germany), which would have difficulty in adapting their present system to the prescribed regime, and were opposed to the superordinacy of the EU organs over national regulatory bodies. Until now, all drafts have been rejected.

The Commission intends to issue annual reports summarizing progress in this area. The first annual report, published in 2005, admits that the financing of decommissioning is a complex issue, and that various approaches can be taken. However, the creation of an international market has brought an increased need for transparency and harmonization in the management of financial resources in liability funds. The Commission also stated its opinion that methods of financing should be harmonized in due course. The Commission announced that it will draft its Recommendation in this area. This has now been submitted for comments by the member states.

The Recommendation reiterates the obligation to decommission an installation after permanent shutdown, to properly address waste, the polluter pays principle, the availability of financial resources in due time. The recommendation goes on to establish reporting obligations regarding decommissioning plans, and proposes the establishment of a Decommissioning Funding Group on a supranational level. On the national level, the Commission requires member countries to set up a national body, which should provide expert judgments on liability assessment, but should remain independent from the contributors to the fund. Cost assessment and the accessibility of the gathered financial resources should be reviewed periodically, at least once in 5 years. The national body should report annually to the Commission on the conclusions of its proceedings. Nuclear utilities should set up adequate funds on the basis of the revenues obtained from their nuclear activities during the designed lifetime of the installation. The commission prefers external funds, and all new nuclear installations will be required to set up ring-fenced external funds. Decommissioning and waste (+ spent fuel) liabilities must be assessed independently. More expensive options must be taken as the basis for assessment. Any shortfall in financing must be covered by the operators. Financial resources in funds should be invested with a low and secured risk profile. For ring-fenced external funds, the return on the investments should be guaranteed by the state even if a nominal loss is made by the independent manager of the invested funds. If the fund is internal, the operator should establish a segregated fund within its account to make financial resources gathered for nuclear liabilities identifiable and traceable at any given time.

The European Parliament strongly supports these initiatives of the European Commission and has been pursuing its own initiatives in this area.

\section{Liabilities in the Czech Republic}

The Atomic Energy Act (18/1997 Coll.), as fundamental legislation regulating nuclear installations, was passed in 1997. This legislation set the main responsibilities and liabilities in spent fuel management, radioactive waste management and decommissioning of nuclear installations. The basic principles have been extended and specified by implementing legislation (governmental decrees, State Office for Nuclear Safety regulations).

ČEZ, a.s. (ČEZ), the operator of nuclear power plants in the Czech Republic, has been establishing reserve funds to cover nuclear liabilities since 1993. Before the passage of the Atomic Energy Act in 1997, the setting-up of these funds was based on company's own decision and the funds could not be claimed against costs.

The Atomic Energy Act establishes that the state is responsible for safe disposal of nuclear waste. The Radioactive Waste Repository Authority (RAWRA) as the state agency that is responsible in the area of radioactive waste and radioactive waste disposal. In accordance with the "polluter pays" principle, producers of radioactive waste make payments into the so 
called Nuclear Account, which is held at the Czech National Bank. RAWRA activities are financed from this account. The funds are put into safe investments specified in Atomic Energy Act to cover inflation effects and to achieve some real interest over and above inflation.

Spent fuel is not considered as radioactive waste until its producer declares it as such and transfers it to RAWRA for disposal. All future costs connected with intermediate storage of the fuel and with the transportation to the RAWRA repository must be borne by the operator. These costs comprise the construction, operation and decommissioning costs for intermediate storage, the purchase costs of dry casks, and also the costs of transportation to the deep repository. ČEZ decided to create an accounting reserve to cover all future liabilities connected with storage and transport of spent fuel. This accounting reserve was set up on the basis of a decision of ČEZ, a. s., and not in accordance with Atomic Energy Act and, therefore it cannot be claimed against costs. The IAS 37 international accounting standard requires ČEZ to consider this liability in its balances, it is regularly checked by the external auditor.

According to Czech national radioactive waste policy, a deep geological repository should be in operation in 2065 . RAWRA is responsible for its siting, development, construction, operation, closure and monitoring. The repository will have to be in operation for a sufficiently long period to dispose of the accumulated spent fuel and other waste (long-life and high activity waste from plant operation and decommissioning).

ČEZ, the nuclear power plant operator has paid into the Nuclear Account since 1997. Currently it pays 50 CZK on MWh generated in its nuclear power plants. This fee covers future costs for spent fuel disposal, and also for disposal of operational low and medium active waste.

The operators of research reactors pay to the Nuclear Account a fee based on the heat generated in the reactor. Small producers pay specified fees when their waste is transferred.

A near-surface low and intermediate waste repository is in operation on the site of the Dukovany nuclear power plant. Mainly operational waste from thee Dukovany and Temelín plants is disposed off there. ČEZ operates the repository as a contractor for RAWRA. The second repository in operation is the Richard repository, in Northern Bohemia, close to town Litom ice. It is used for institutional radioactive waste. The Bratrství repository, in a former uranium mine in Western Bohemia, is used only for natural isotopes.

As concerns decommissioning of nuclear installations, operators are required to create reserve fund in the form of a blocked account at a reputable bank. Cost assessment and the state of the reserve are audited by RAWRA. All uses of the blocked account must have RAWRA approval. Cost assessment is reviewed at 5 years intervals. Studies and cost assessments must be performed not only for nuclear power plants, but also for other nuclear facilities, e.g. spent fuel storage facilities.

If we compare the state of nuclear liabilities in the Czech Republic with the Recommendations of the European Commission, we can state that the Czech Republic already complies with the main requirements. Individual liabilities are assessed independently, sufficient financial resources have been accumulated and the adequacy of the funds has been periodically checked. The decommissioning fund is managed by the operator and not by the State. However, the State controls the use of this fund via its agency RAWRA.

The Atomic Energy Act defined responsibilities in the Czech Republic as follows:

Table 2: Division of responsibility in the Czech Republic

\begin{tabular}{|c|c|c|c|}
\hline & Spent fuel & Rad. waste & Decomm. \\
\hline $\begin{array}{l}\text { Legal } \\
\text { responsibility }\end{array}$ & $\begin{array}{l}\text { Storage - } \\
\text { operator } \\
\text { Disposal - } \\
\text { State }\end{array}$ & \begin{tabular}{|} 
Storage - pro- \\
ducer \\
Disposal - \\
State
\end{tabular} & $\begin{array}{c}\text { Plant } \\
\text { operator }\end{array}$ \\
\hline $\begin{array}{l}\text { Financial } \\
\text { resources }\end{array}$ & $\begin{array}{c}\text { Plant } \\
\text { operator }\end{array}$ & $\begin{array}{l}\text { Waste } \\
\text { producer }\end{array}$ & $\begin{array}{c}\text { Plant } \\
\text { Operator }\end{array}$ \\
\hline Form & $\begin{array}{l}\text { Storage - } \\
\text { acc.res. } \\
\text { Disposal - } \\
\text { Nucl. Acc. }\end{array}$ & $\begin{array}{l}\text { Storage - } \\
\text { acc.res. } \\
\text { Disposal - } \\
\text { Nucl. Acc. }\end{array}$ & $\begin{array}{l}\text { Blocked } \\
\text { Account of } \\
\text { Operator }\end{array}$ \\
\hline
\end{tabular}

\section{Assessment of liability}

Future costs are modeled on the basis of technical studies and appraisals of individual activities. The cost studies are usually performed in fixed prices in the year of the study. If we consider cost escalation (not identical with inflation, as storage and repository costs grow less than inflation, which is led by service costs), we have to recalculate the cost estimates from the fixed costs (e.g. from the year 2005) to the current prices in the year when the appropriate amount of money will be expended.

$$
S_{t}=S_{\mathrm{fix} t} \prod_{n=1}^{t}\left(1+E S C_{n}\right),
$$

where $S_{t}$ is expenditure (cost) in year $t$ in current prices, $S_{\text {fix } t}$ is expenditure (cost) in year $t$ expressed in fixed prices from the year of study. $E S C_{n}$ is escalation factor between years $n$ and $n-1$.

The basic principle is that financial resources must be accumulated during the operational lifetime of the nuclear power plant. Various "technical" unit options can be used for calculating the operator's regular payments. For decommissioning, fixed annual payments are very often considered (liability is not in a principle function of the volume of electricity generated). For spent fuel and radioactive waste, generated electricity is usually used as the basis for calculating the operator's payment. For a certain period a certain rate is declared, this is used for calculating the payment (e.g. $50 \mathrm{CZK} / \mathrm{MWh}$ ). This rate can be found by calculating the base rate $R_{\text {base }}$ in following way:

Firstly we introduce the effective rate in year $t$, which can be calculated as 


$$
R_{\mathrm{ef} t}=R_{\text {base }} \prod_{n=1}^{t}\left(1+D_{n}\right),
$$

where $R_{\text {base }}$ is the basic rate to be paid into the fund per MWh generated in power plants in the first year of the analyzed period, $D_{n}$ is the increment in the rate between years $n$ and $n-1$.

The concept of an effective rate is logical. The rate should constitute constant proportion of the costs of electricity, and with the gradual effect of inflation also the rate should also increase.

Then we define cash-flow in year $t$

$$
C F_{t}=\left(E_{t} R_{\mathrm{ef} t}-S_{t}\right),
$$

where $E_{t}$ is generation of the nuclear power plants in year $t$, $R_{\text {ef } t}$ is the effective rate in year $t, S_{t}$ is expenditure from the fund in year $t$.

Finally by solving following formula introducing (1), (2) and (3) (e.g. in spreadsheet using a solver) we find sought $R_{\text {base }}$

$\left(\ldots\left(\left(C F_{1}\right)\left(1+Y_{1}\right)+C F_{2}\right)\left(1+Y_{2}\right)+\ldots+C F_{T}\right)\left(1+Y_{T}\right)=0$,

where $Y_{t}$ is the rate of yield of invested financial means from the fund in year $t, T$ is year when nuclear liability is fully settled.

A very important boundary condition is that summation of first $n$ cash-flows $(n=1 \ldots T)$ in formula (4) is always $\geq 0$.

The above formulas assume a variable investment yield rate, inflation rate and increment in the rate. However, it is very difficult to predict these factors over the very long periods involved. For practical purposes we consider them to be constant for the whole period under consideration. Then if we suppose constant rate, we can calculate simplified rate $R_{\text {simpl }}$

$$
R_{\text {simpl }}=\frac{\sum_{t=1}^{T} S_{t}(1+E S C)^{-t}}{\sum_{t=1}^{T} E_{t}(1+I)^{-t}} .
$$

Example of typical balance of the "nuclear account" (hypothetical) is shown on the following graph in Fig. 1.

Fig. 1 shows that the operator pays into the Nuclear Account only during the operation of the power plants (1997-2042). During this period substantial financial resources accumulate. Investment of the available resources

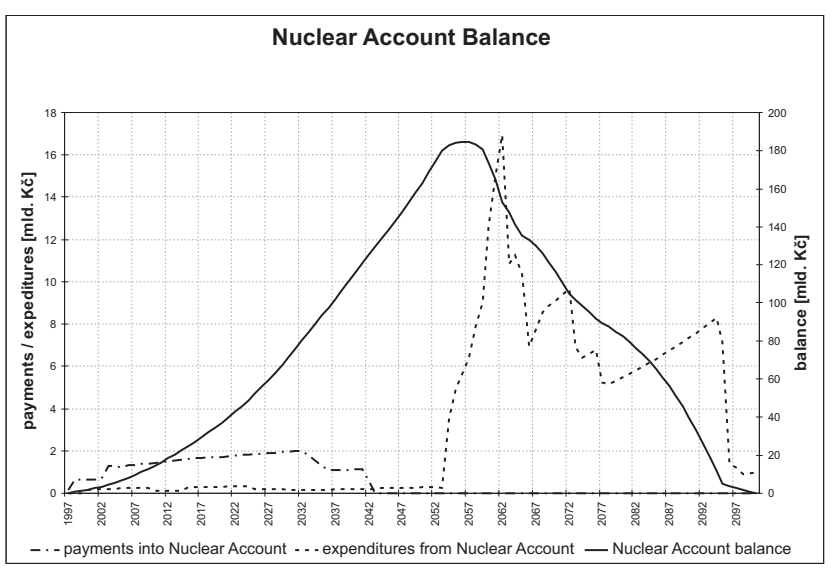

Fig. 1: Hypothetical balance of a nuclear account in CR from the Nuclear Account leads to further growth of the Nuclear Account. When the process of disposal is completed (the repository is decommissioned), the balance of the Nuclear Account is zero. The cost assessment includes some extra costs to cover contingencies and risk.

\section{Conclusions}

Nuclear liability must be carefully assessed and controlled, because failure to meet this liability can lead to serious environmental and economic consequences. The probability of failure to meet nuclear liability is decreasing, as this area is now becoming a subject of supranational regulation, especially in the European Community. The liability assessment methodology is well developed, and control mechanisms are being enhanced.

The Czech Republic is very advanced in covering nuclear liabilities. It has already adopted the main principles recommended by the European Commission. Model calculations have been made, and the assumptions used in the model have been verified. The calculations show that liabilities of the nuclear power plant operator are well covered.

\section{Acknowledgments}

I would like to express my sincere thanks to J. Knápek and J. Vašíček from Department of Economics, Management and Humanities for their support and long-term cooperation in the area of nuclear liabilities, and to my colleagues from ČEZ's Fuel Cycle Section for our wonderful working relationships.

\section{References}

[1] International Accounting Standard IAS 37 Provisions, Contingent Liabilities and Contingent Assets.

[2] The European Commission, Directive 2003/54/EC of the European Parliament and of the Council of June 2003 concerning common rules for the international market in electricity and repealing Directive 96/92/EC, Brussel, 26 June 2003.

[3] The European Commission, Communication to the European Parliament and the Council Report on the use of financial resources earmarked for the decommissioning of nuclear power plants, COM (2004) 719, Brussel, 16 October 2004.

[4] Atomic Energy Act, Law 18/1997 of Collection as Amended.

Ing. Ladislav Havlíček

e-mail: havlil10@email.cz

Dept. of Economics, Management and Humanities

Czech Technical University in Prague

Faculty of Electrical Engineering

Technická 2

16627 Praha 6, Czech Republic 